\title{
La Colombia de Pedro Sonderéguer desde la atalaya bonaerense de La Nación
}

Maryluz Vallejo ${ }^{1}$

Recibido: 04/03/2019

Aprobado por pares: 19/06/2019
Enviado a pares: 04/04/2019

Aceptado: 26/06/2019

DOI: 10.5294/pacla.2019.22.4.5

Para citar este artículo / to reference this article / para citar este artigo

Vallejo, M. (2019). La Colombia de Pedro Sonderéguer desde la atalaya bonaerense de La Nación. Palabra Clave, 22(4), e2245. DOI: https://doi.org/10.5294/pacla.2019.22.4.5

\section{Resumen}

Pedro Sondéreguer (Villanueva, Bolívar, 1884-Buenos Aires, 1964) realizó su "sueño argentino" en el prestigioso diario La Nación en la primera mitad del siglo XX. Desde allí cultivó un proyecto americanista y colombianista que no logró materializar, pero quedó recogido en su obra periodística — olvidada tanto en su país natal como en el de adopción- y en las múltiples entrevistas que le hicieron en la prensa colombiana y extranjera. ¿Por qué Sonderéguer no regresó a Colombia cuando se instauró la República Liberal y su nombre sonaba para ocupar altos cargos en el Gobierno de Enrique Olaya Herrera, si tenía todas las credenciales para ejercer la política y el periodismo? Es la pregunta que apuntala este artículo inspirado en la teoría del acontecimiento (F. Dosse) con sus enigmas y reinterpretaciones constantes en torno a la biografía de un intelectual. Tras esbozar la línea editorial del diario La Nación, fundado en 1870 por Bartolomé Mitre, se reconstruye la trayectoria del escritor y periodista a partir de las escasas notas biográficas existentes y de testimonios de sus congéneres y familiares. Por último, se interpretan sus ideas políticas, en concreto,

1 https://orcid.org/0000-0002-1552-1023. Pontificia Universidad Javeriana, Colombia. maryluz.vallejo@javeriana.edu.co 
sus proyectos de estadista que buscaban impulsar el desarrollo económico en Colombia, y se analizan sus actuaciones según el contexto de la época para tratar de responder a la pregunta planteada. Con el rescate de este autor, no solo se hace un aporte a la historia del periodismo colombiano y argentino, sino también a la historia política colombiana, en los albores de la llamada República Liberal marcados por la guerra con el Perú y los brotes de la violencia partidista.

\section{Palabras clave (Fuente: tesauro de la Unesco)}

Historia política; prensa; periodismo; historia del periodismo; Colombia; Argentina; biografía. 


\section{Pedro Sonderéguer's Colombia from the Buenos Aires Vantage Point of La Nación}

\section{Abstract}

Pedro Sondéreguer (Villanueva, Bolívar, 1884-Buenos Aires, 1964) made his "Argentine dream" come true in the prestigious newspaper La Nación in the first half of the 20th century. From there he conceived an Americanist and Colombianist project that he failed to bring to life, but was noticeable in his journalistic work - forgotten both in his home and adoptive countries - and in multiple interviews he gave to the Colombian and foreign press. Why did Sonderéguer not return to Colombia when the Liberal Republic was established and his name was mentioned for high positions in Enrique Olaya Herrera's administration, if he had all the credentials to practice politics and journalism? It is the question underpinning this article inspired by F. Dosse's theory of the event with its enigmas and constant reinterpretations of the biography of an intellectual. After outlining the editorial line of La Nación, founded by Bartolomé Miter in 1870, the writer and journalist's career is reconstructed from scarce biographical notes and testimonies of his peers and relatives. Finally, his political ideas are construed, specifically his statesman projects that sought to boost economic development in Colombia, and his actions are analyzed in the context of the time to attempt to answer the question posed. In reviving this author, a contribution is made not only to the history of Colombian and Argentine journalism, but also to Colombian political history at the dawn of the so-called Liberal Republic marked by the war with Peru and the outbreaks of partisan violence.

\section{Keywords (Source: Unesco Thesaurus)}

Political history; press; journalism; history of journalism; Colombia; Argentina; biography. 


\section{A Colômbia de Pedro Sonderéguer a partir da atalaia bonaerense de La Nación}

\section{Resumo}

Pedro Sondéreguer (Villanueva, Bolívar, 1884-Buenos Aires, 1964) realizou seu "sonho argentino" no prestigioso jornal La Nación, na primeira metade do século XX. A partir disso, cultivou um projeto americanista e colombianista que não conseguiu materializar, mas que ficou consagrado em sua obra jornalística - esquecida tanto em seu país natal quanto no de adoção - e nas múltiplas entrevistas que lhe foram feitas na imprensa colombiana e estrangeira. Por que Sonderéguer não voltou à Colômbia quando a República Liberal foi instaurada e seu nome era citado para ocupar altos cargos no governo de Enrique Olaya Herrera, se tinha todos os requisitos para exercer a política e o jornalismo? Essa é a pregunta feita neste artigo inspirado na teoria do acontecimento (F. Dosse) com seus enigmas e reinterpretações constantes em torno da biografia de um intelectual. Após esboçar a linha editorial do jornal La Nación, fundado em 1870 por Bartolomé Mitre, é reconstruída a trajetória do escritor e jornalista a partir das escassas anotações biográficas existentes e de depoimentos de seus congêneres e familiares. Por último, são interpretadas suas ideias políticas, em específico, seus projetos de estadista que pretendiam promover o desenvolvimento econômico na Colômbia, e são analisadas suas ações segundo o contexto da época para tentar responder à pergunta proposta. Com o resgate desse autor, não somente se contribui para a história do jornalismo colombiano e argentino, mas também para a história política colombiana, no início da chamada "República Liberal”, marcado pela guerra com o Peru e pelos surtos de violência partidária.

\section{Palavras-chave (Fonte: tesauro da Unesco)}

História política; imprensa; jornalismo; história do jornalismo; Colômbia; Argentina; biografia. 


\section{Introducción}

A comienzos del siglo XX, Argentina fue la estación previa a París para muchos intelectuales colombianos. La prensa bonaerense, con su modelo republicano defensor de las libertades ciudadanas y su avanzada industria editorial, sobresalía en el mundo de habla hispana. Por ello, Pedro Sonderéguer, al igual que otros intelectuales y escritores colombianos, como Baldomero Sanín Cano, Alberto Lleras Camargo, Germán Arciniegas y Luis Enrique Osorio Morales, realizó su "sueño argentino" en el prestigioso diario La Nación de Buenos Aires, al que se vinculó en $1908 .{ }^{2}$ Recién llegado de Chile, donde vivió un año, se atrevió a escribirle a "Bartolito" Mitre, el hijo del general Bartolomé Mitre, fundador y director del periódico, y consiguió que lo contrataran a sus 24 años.

Comenzó a escribir en el suplemento dominical donde publicó artículos, cuentos y poemas, y pronto ascendió a jefe de redacción, editor de la sección internacional y columnista. Desde esa tribuna de opinión promovió un proyecto americanista y colombianista que quedó consignado en los artículos publicados durante más de cuarenta años en el prestigioso diario porteño donde se jubiló en 1954. Allí alternó el trabajo periodístico con su obra literaria y filosófica, contenida en más de treinta libros, y de la que no nos ocuparemos en este artículo, acotado a su producción periodística. ${ }^{3}$

Pese a que en Colombia personaje y obra cayeron en el completo olvido, en sendas visitas que realizó al país, en 1928 y 1931, Sonderéguer fue objeto de homenajes, agasajos y de primeras planas con gran despliegue en los principales diarios regionales y nacionales, donde se elogió su perfil de polímata, a la altura del maestro Sanín Cano. Tras su frustrado intento de participar en el Gobierno liberal de Enrique Olaya Herrera, no regresó a Colombia y murió en Buenos Aires en 1964, pero nunca dejó de escribir sobre su país como un estadista deseoso de transformarlo.

\section{Metodología}

En primer lugar, se perfila la línea editorial del diario La Nación a partir de las voces de historiadores argentinos (Sidicaro, 1993; Ulanovski, 2011) y de

2 Su primera columna la publicó el 25 de abril de 1908.

3 Valga anotar que el académico Raymond Williams en su libro Novela y poder en Colombia 1844-1987 (1991, p. 137) hace alusión a una de las novelas de Sonderéguer, Cátedra de seducción (1924). 
periodistas colombianos que se formaron en esa privilegiada sala de redacción. En segundo lugar, se traza la semblanza de Sonderéguer con apoyo en los textos de su único biógrafo y paisano de Villanueva Fidel A. Leottau Beleño y en el archivo personal del escritor facilitado por su primer nieto Pedro Conrado Sonderéguer, residente en Buenos Aires, cuya memoria -en parte recogida de su padre, Conrado - fue esencial para armar este relato.

Por último, se analiza un corpus de artículos de Sonderéguer relacionados con sus ideas de progreso para Colombia, especialmente para el departamento del Chocó, que lo obsesionó hasta el punto de volverlo escenario de una de sus novelas (Quibdó, 1927). En este apartado, enmarcaré los debates políticos que con mentalidad de estadista dejó servidos en declaraciones públicas y en escritos periodísticos.

Conceptualmente, retomo la noción de biografía intelectual de Dosse (2013), que se inserta en la corriente del género biográfico vinculado al concepto de acontecimiento; mejor aún, del renacimiento del acontecimiento, "que no se trata del retorno de lo mismo, sino de algo diferente" (Pons, 2010). Para Dosse, "hoy en día la manera de abordar tanto una biografía como la problemática del acontecimiento es más reflexiva, ya que se tienen en cuenta las condiciones de posibilidad, las zonas de opacidad, el hecho de que existen lógicas de las cuales los actores no son conscientes, etc." (citado por Pons, 2010). Así como la biografía ya no puede limitarse al relato lineal de una vida, la noción de acontecimiento retorna con dos rostros: el de enigma (esfinge) y el de reinterpretación constante (fénix) (Dosse, 2013). Dosse también se aproxima a la construcción de identidades políticas, noción rentable para explorar esta faceta de Sonderéguer, quien estaba llamado a ocupar altos cargos en la naciente República liberal.

\section{Los aires intelectuales de La Nación que aspiró Sonderéguer}

El diario La Nación, fundado en 1870 por el historiador Bartolomé Mitre, ofrecía la mejor escuela de periodismo en habla hispana con una red de corresponsales en el país y en el exterior, y más de 4000 personas a su servicio, además de moderno equipamiento (Barrera, 2004, p. 158). El primero 
que aprovechó la experiencia fue Baldomero Sanín Cano, como lo cuenta en sus memorias, al tiempo que resalta la presencia de Sonderéguer:

\begin{abstract}
La Nación no era un simple rotativo, sino una fortaleza intelectual que acogía el pensamiento y el arte del mundo entero y animaba con su hospitalidad la conciencia latinoamericana. Allí tuve la honra de trabajar con inteligencias de primera categoría, como las de Luis Murature, Alberto Gerchunoff, Alfonso de Laferrere, Enrique Loncan, Gustavo Cancela, y otros muchos que después han descollado en las letras y en la política argentina. A nadie se preguntaba allí de dónde venía. Estaba en Argentina y esa era la mejor noticia. En todas las redacciones había sudamericanos en quienes la cordialidad de la metrópoli desvanecía el rótulo de patria chica; y entre ellos recuerdo como compañero de trabajo en la misma Nación, al cartagenero $0^{4} \mathrm{Pe}-$ dro Sonderéguer, una de las plumas más populares de Buenos Aires y uno de nuestros más afirmativos pensadores. $(1949$, p. 29)
\end{abstract}

El escritor y periodista colombiano Luis Enrique Osorio, quien también tuvo su periplo argentino, trascribió apartes de una entrevista con el subdirector de La Nación, Juan Santos Valmaggia (1964), ${ }^{5}$ quien acababa de recibir el Premio María Moors Cabot por su lucha por la integración interamericana, así como lo recibió Luis Mitre, descendiente del fundador: Bartolomé Mitre, declara Valmaggia, pertenece a esos grandes americanos que tuvieron que empuñar a la vez la pluma y la espada, y que antes de triunfar como estadistas tuvieron que sufrir y luchar en el exilio a causa de los tiranos. Pero la peculiaridad de su obra consiste en que fundó $\mathrm{La}$ Nación, no para abrirse paso hacia la Presidencia de la República, sino para superarse como orientador intelectual cuando dejó de ser gobernante. Durante su periodo presidencial tuvo como órgano de gobierno al diario $\mathrm{La}$ Nación Argentina. Al dejar el mando, lo transformó en La Nación, empresa a la que consagrará todos sus esfuerzos y entusiasmos hasta morir en 1906.

Según Valmaggia, el periódico mantuvo total neutralidad para apoyar o censurar los actos de los gobiernos. "En materia política combatió siempre los fraudes electorales, padeciendo por esta causa cinco clausuras en

4 Numerosos autores revisados en el corpus aluden al periodista "cartagenero", aunque nació en Villanueva, un pueblo cercano a la capital de Bolívar.

5 Osorio Morales (El Tiempo, enero de 1964), columna Visión de América: "El diario La Nación en la vida argentina". 
sus primeros 25 años de vida, y teniendo que recurrir dos veces a la revolución". Osorio resalta en ese artículo la posición americanista de La Nación y menciona como acierto haber contado entre sus colaboradores con José Martí, Rubén Darío, Miguel de Unamuno, Remy de Gourmont, Julián Marías, José Ortega y Gasset, Juan Valera, Charles Maurras, entre muchas otras plumas que también figuraron en la Biblioteca de La Nación, y que de 1900 a 1914 lanzó más de 800 volúmenes a precios populares.

"Cuando funda La Nación, lo que Mitre pretende es tener un diario que contribuya a consolidar la organización nacional”, dijo en 1996 el secretario de redacción José Claudio Escribano, quien reconoció el criterio pluralista del diario, a la vez conservador y liberal (Ulanovsky, 2011, p. 24). El diario nació en 1870 como una "tribuna de doctrina", según el propio Mitre. Por su parte, Osorio Morales escribió sobre La Nación: "En materia económica es contrario al desaforado intervencionismo estatal que caracterizó al régimen peronista”. El diario apoyó la revolución de 1955, que derrocó a Perón, pero no cerró del todo filas por Frondizi, y mantuvo una postura crítica frente a los sucesivos gobernantes (Osorio, 1964). ${ }^{6}$

En un artículo publicado en El País de Madrid (2014) sobre los diarios argentinos más importantes en el centenario de la llamada Revolución de Mayo, se resaltan La Prensa y La Nación. Como ocurría en América Latina, los diarios surgían al calor de los proyectos políticos, y aunque hay una historia detallada del periodismo argentino, afirma el autor que son prácticamente inexistentes los estudios del periodo del centenario (mayo de 1910). De La Nación, Mayocchi (2014) recuerda que "el 26 de junio de 1901, al cumplir Mitre ochenta años de edad, su diario frisaba en los treinta y uno. Los 1.000 ejemplares de cuatro páginas cada uno publicados el 4 de enero de 1870 se habían multiplicado cerca de cien veces”. Ideológicamente, Mayocchi relaciona La Nación con la corriente política de los mitristas, cuyo número era todavía importante en la provincia de Buenos Aires. Así lo sería hasta 1909, cuando se declaró independiente de todo partido político tras la muerte de Emilio Mitre. La empresa editorial, ya constituida en sociedad anónima de familia, pasó a ser dirigida por Jorge Adolfo Mitre, nie-

6 Osorio Morales (El Tiempo, enero de 1964), columna Visión de América: "El diario La Nación en la vida argentina". 
to del fundador y "gran renovador de las formas periodísticas vigentes hasta entonces en el país”.

Pero este heredero del emporio periodístico le mereció poco respeto a Alberto Lleras Camargo, quien en una carta que dirigió a Sonderéguer se refiere al propietario de La Nación como "un diocesillo menor que rige los destinos de toda la inteligencia del Sur" (Leottau, 2005, p. 220). Claro que Lleras Camargo tampoco escribió con entusiasmo sobre Pedro Sonderéguer en sus memorias: "Una especie de filósofo y cuentista cartagenero que escribía en La Nación" (1997, p. 252). No obstante, la correspondencia que se cruzaron ambos fue copiosa y devela una sincera amistad, según su biógrafo Lottau Beleño.

Aparte de simpatías o antipatías, el diario cercano a las librerías de la calle Florida ofrecía el ambiente intelectual propicio a los escritores que vivían del oficio de periodistas. Eso habrá atraído más a Sonderéguer que las posturas políticas de sus directores, con quienes tuvo desavenencias en distintas épocas, básicamente por su posición no especialmente probritánica durante las dos guerras mundiales, recuerda su nieto Pedro Conrado.

\section{"Un colombiano que es célebre en Argentina"}

Así se tituló la entrevista que le hizo a Sonderéguer el ya citado Luis Enrique Osorio Morales (Cromos, 30 de marzo de 1922). De entrada, señala que el popular filósofo y novelista "consagrado en la desembocadura del Plata era un personaje desconocido para los atenienses de la Sabana ${ }^{7}$." Afirma que los libros de Sonderéguer, que se agotan en el sur, no han llegado a Colombia. A los 15 años se aventuró por el mundo y después de vivir en Jamaica, Cuba y en Costa Rica — donde publicó su primera novela, Cóndor, a los 19 años— "sentó plaza en Buenos Aires, en 1908. A los dos meses ya era redactor de La Nación, donde, entre otras cosas, publicó varios artículos sobre Colombia”.

7 El gentilicio es irónico por aquello de que Bogotá era conocida como la "Atenas Suramericana”. 
Tras dieciséis años de vivir en Argentina, le precisa Sonderéguer al periodista que ha seguido muy de cerca el desarrollo de su país, “y soy patriota como el que más. Mi mayor deseo es poder servir a Colombia algún día de manera acertada, para lo cual he venido estudiando año tras año más de lo que usted se imagina”. Como su preparación se enfocaba en las finanzas y en la economía política, el periodista le preguntó por las reformas que necesitaba su país, a lo que Sonderéguer respondió:

\begin{abstract}
¿Reformas? El régimen impositivo de Colombia es bárbaro. De allí se deduce que el Gobierno nunca pueda atender a las necesidades primordiales de la Nación. En Colombia no hay nada que reformar en ese sentido. La contabilidad es deficiente. Es preciso hacerlo todo. Colombia no solo es el país donde menos impuestos se cobran, sino el único que con el nombre de civilizado adopta el sistema de vender las rentas públicas. Ni siquiera se puede fijar con exactitud lo que debe pagar cada ciudadano porque no existe un cálculo aproximado del monto de la riqueza pública. (Cromos, 30 de marzo de 1922)
\end{abstract}

Al final de la entrevista le preguntó Osorio Morales a Sonderéguer si era cierto que publicó en La Nación una entrevista con el expresidente Rafael Reyes, "quien declaró que le hallaba la razón al Perú en los asuntos de la Casa Arana”. Al día siguiente, el general Reyes rectificó, y de inmediato tuvo que salir para Chile. ${ }^{8}$

El 25 de abril de 1958, La Nación le celebró las bodas de oro como periodista, ya que publicó su primera columna el 25 de abril de 1908. En 1910, fue secretario de la delegación colombiana en la Conferencia Panamericana de Buenos Aires y en 1916 fue delegado por Colombia a las fiestas del centenario de la independencia política argentina. Desde entonces se destacó en matemáticas, metafísica, economía política, ingeniería, sociología, psicología y hasta metafísica.

8 Cuarenta años después, cuando se encontraba radicado en Argentina, en su columna Visión de América de El Tiempo (diciembre de 1963), Osorio Morales contó que hizo un viaje de casi una hora desde Buenos Aires para visitar "a nuestro filósofo colombo-argentino Pedro Sonderéguer”. Afirmó que el “argentino” era un europeo trasplantado que vivía en Argentina mejor que en su país de origen, pero conservó con orgullo su nacionalidad colombiana. Destacó la tendencia social de su obra que propendía a la civilización de los países americanos, las nuevas repúblicas, entre las que Colombia era su principal laboratorio de observación. 
La biografía de Pedro Sonderéguer no figura en la historia del periodismo colombiano, sino en un blog sobre inmigración y literatura en Argentina de la profesora María González Rouco (Leottau, 2009) quien siguió las pistas de un paisano de Pedro Sonderéguer: Fidel A. Leottau Beleño. Según Lottau Beleño, "desde que salió de Villanueva, a los dieciséis años, y después de haber estudiado el bachillerato en Cartagena, en el Colegio Martínez Olier, Pedro Sonderéguer emprendió un periplo que empezó en Jamaica, continuó en Cuba, Estados Unidos y, sucesivamente, en Costa Rica, Perú, Panamá, Chile y Argentina, en donde se radicó en el año 1908”.

Su nieta, María Sonderéguer, ${ }^{9}$ experta en literatura argentina y profesora de la Universidad de Buenos Aires, cuenta que su bisabuelo era un ingeniero civil suizo alemán, de apellido Sonderegger, que vino a Colombia a finales del siglo XIX a trabajar con la empresa constructora del canal de Panamá propiedad de Ferdinand de Lesseps, y se casó con Cayetana Villanueva, oriunda de un pueblo bolivarense del mismo nombre. A su único hijo, Pedro, lo mandó a estudiar ingeniería en la Universidad de Notre Dame, en Indiana, Estados Unidos, pero este, llevado por su vocación literaria, siguió su trashumancia hacia el sur del continente y de paso castellanizó su apellido. En abril de 1917, fundó un semanario llamado La Revista, empresa de carácter político para estudiar los problemas de Argentina y del continente, donde lo acompañó Segundo Moreno. "La Revista — reza el prospecto - es una publicación eminentemente argentina, pero combatirá el nacionalismo ramplón y el patrioterismo criminal, bajo cuya careta el país ha sufrido enormes perjuicios morales y materiales". Para entonces, Sonderéguer era considerado "un cerebro vigoroso, amigo de ahondar en las cuestiones sociólofilosóficas, vinculado a la vida intelectual y periodística de Argentina" (La Nación, 13 de abril de 1917).

Pese a que solo regresó a Colombia en 1928, Sonderéguer se mantenía al tanto del acontecer en su país, sobre todo de las acciones del Partido Liberal en la oposición. Repetidas veces los diarios argentinos consultaban su opinión en periodos electorales, como se puede comprobar en los recortes de prensa que cuidadosamente archivó. Y esa estrecha vigilancia de

9 Entrevistada por Julio de La Hoz el 27 de septiembre de 2011, en Buenos Aires, por encargo de la autora de este artículo. 
las acciones de su partido fue una constante en sus escritos. Por ejemplo, a propósito del nombramiento del político y periodista conservador Carlos E. Restrepo como presidente para el periodo de 1910 a 1914, Sonderéguer reconoció que el periodismo es el campo de donde salen los mejores mandatarios. Y el 19 de septiembre de 1913 salió publicado un artículo en La Tribuna de Buenos Aires sobre los candidatos a la Presidencia de Colombia en el periodo de 1914 a 1918. En la entrevista, reconoció que el conservatismo tenía dos candidatos fuertes, Marco Fidel Suárez y José Vicente Concha, mientras el liberalismo no tenía candidatos porque era una colectividad muy fraccionada. Incluso desde antes había manifestado su apoyo al presidente Carlos E. Restrepo, a quien redoblaba la admiración por su condición de periodista. ${ }^{10}$

\section{Los dos viajes a Colombia}

Aunque el nombre de Sonderéguer estuvo en el sonajero del Partido Liberal en 1923, cuando el diario El Tiempo lanzó la idea de que en la plancha de los candidatos al Senado por Cundinamarca fueran incluidos destacados colombianos que vivían en el exterior, entre ellos, Baldomero Sanín Cano y Pedro Sonderéguer (El Diario Nacional, 2 de abril de 1923), la postulación no se concretó y el escritor solo regresó a Colombia en 1928, tras veintidós años de su partida.

Con motivo de ese viaje, periódicos de Argentina y de Chile lo entrevistaron para conocer sus impresiones sobre Colombia, y él, posiblemente más enterado que cualquier congresista colombiano, respondió siempre con cifras y proyecciones basadas en sus infatigables estudios. El Diario Ilustrado de Santiago de Chile ( 5 de febrero de 1928) publicó una extensa entrevista donde Sonderéguer se refirió a las riquezas naturales de ese territorio de más de un millón de metros cuadrados, que ocupaba el segundo puesto en la producción mundial del café y esperaba incrementar la explotación de petróleo con un nuevo oleoducto de más de seiscientos kilómetros a un costo de treinta millones de dólares. Todo este empuje, según Sonderé-

10 Tiempo después el expresidente conservador alabó la novela de Sonderéguer Quibdó (1927), de la que destacó la verosimilitud de la narración y la construcción de los personajes. Se refirió a él como el "gran Embajador intelectual de Colombia en Argentina” (Leottau, 2005, p. 221). 
guer, atraería una importante inmigración espontánea a Colombia, necesaria para alcanzar el progreso.

Según La Nación — que publicó todos los detalles de este primer viaje de Sonderéguer a Colombia- el escritor partió de Buenos Aires el 2 de febrero de 1928 e hizo escala en Chile, para recibir varios homenajes y agasajos. De Valparaíso siguió rumbo a Cartagena y en Villanueva visitó a su familia, en especial a su madre, Cayetana, con quien salió retratado en algunos diarios de la Costa. Su llegada fue muy comentada en los periódicos de la época porque en todas las ciudades adonde llegó recibió trato de celebridad y primeras planas en los periódicos regionales y bogotanos. En el álbum familiar, se encuentra la invitación al banquete que ofreció la Asamblea Departamental de Bolívar al insigne escritor en el Hotel Americano de Cartagena, el 16 de marzo de 1928. En su posterior visita a Barranquilla, siempre fue portada de los principales diarios La Prensa, El Porvenir, Diario del Comercio, Diario de la Costa, etc.

En este último diario de Cartagena, habló sobre la potente literatura argentina, mencionó que en el Cono Sur los intelectuales colombianos eran poco conocidos, salvo tres o cuatro, y eludió hablar de política colombiana. Señaló con preocupación que el país se estaba urbanizando "con frenesí", lo que estimulaba "la despoblación del campo, fenómeno que suele tener consecuencias lamentables”. Y cuando el periodista le preguntó si finalmente pensaba venirse a vivir a Colombia, afirmó: "En eso estoy pensando" (Diario de la Costa, 3 de marzo de 1928).

El 6 de marzo, La Patria de Cartagena publicó en primera página su saludo al escritor; asimismo, reseñó el homenaje que le hicieron en el Club Cartagena. Igual despliegue dio El Diario del Comercio de Barranquilla al recibimiento organizado por la Asamblea Departamental de esa ciudad (18 de marzo de 1928). El 19 de marzo, El Tiempo dio la noticia del regreso de Sonderéguer a Buenos Aires después de haber sido objeto de homenajes por parte de diputados y periodistas en las ciudades que visitó. Anunció que regresaría en dos años, y que de los 11 libros y 58 novelas cortas publicadas hasta el momento, el mejor era Quibdó. Por su parte, Mundo al Día 
de Bogotá publicó una fotografía en gran formato de Sonderéguer en Barranquilla, acompañado por los directores del diario La Prensa y otros periodistas (23 de marzo de 1928).

La segunda visita de Sonderéguer a su tierra tuvo principalmente motivaciones políticas, porque, según consta en su correspondencia personal y en notas de prensa, fue llamado por el presidente liberal Enrique Olaya Herrera para asumir un alto cargo en el Ministerio de Relaciones Exteriores o en el de Industrias. ${ }^{11}$ El propio mandatario, en compañía del ministro de Industrias, le ofreció a su llegada a Bogotá un almuerzo de bienvenida. Su nombre también sonó ese año como ministro de Hacienda y gobernador de Bolívar.

Y como en la anterior ocasión, la prensa se rindió a sus pies.

Sonderéguer, según se lee en la nota de La Nación del 21 de enero de 1931, se encontraba en Nueva York y de allíse embarcó con destino a Cartagena. Con motivo de su arribo a Bogotá, ciudad que no conocía, El Tiempo publicó el 12 de febrero de 1931 una nota de bienvenida en primera plana, escrita por el jefe de redacción, Alberto Lleras Camargo, viejo conocido, que lo fue a entrevistar al Hotel Granada para conocer sus impresiones sobre la escena política. Tras presentar al prestigioso escritor, consignó estas "enigmáticas" ${ }^{2}$ líneas:

Alguna vez se trató de traerlo al país y un consejero de Estado nos decía con la mayor ingenuidad: - “Sonderéguer no resulta para nosotros. — ¿Por qué? —Porque sabe mucho". Estamos, pues, ante ese hombre que por su gran cultura no está lo suficientemente preparado para servirle a Colombia... 0 no lo estaba al menos hace un lustro. Contó Sonderéguer que cuando vino a Colombia en 1928, encontró "un importante resurgimiento económico [...] Este año, al poner de nuevo el pie en tierra colombiana, me hallo ante un franco resurgimiento político. La democracia está en marcha, aunque no puede decirse lo mismo de la cultura cívica y de la disciplina social de la nación.

11 Por su dominio de los temas administrativos y económicos recibió el encargo del Ministerio de Industrias de analizar las posibilidades del país para el desarrollo industrial, agrícola y pecuario en las regiones costeras.

12 El adjetivo es licencia de la autora en referencia al concepto usado por François Dosse: el acontecimiento que se mantiene como un enigma en cuanto a las posibles explicaciones. 
A continuación, Sonderéguer hizo un balance del ambiente que encontró en estos términos: los periódicos están "llenos de artículos escritos en lenguaje desesperado", los políticos que han ocupado por largos periodos las corporaciones legislativas pronuncian magníficos discursos, pero no presentan ni un solo proyecto importante en materia de desarrollo. "Escriben bien, pero piensan mal”. Y termina Lleras con esta queja: “¿Qué triste ver talentos como este, afianzados en un gran prestigio argentino, a pesar de ser colombianos, y en actitud de periodista de paso... ! Cuánta fuerza ha perdido así nuestro país y qué grande sería hoy si hubiera sabido aprovechar a sus hombres" (El Tiempo, 12 de febrero de 1931).

También al Hotel Granada fue a entrevistarlo Jorge Zawadzky, director de El Relator de Cali, quien describió a Sonderéguer como una figura ascética y mística que parecía salida de un lienzo de Zurbarán. A otros periodistas les llamó la atención que pusiera una máquina de escribir al frente de ellos y les dictara las respuestas a sus preguntas para que no lo fueran a distorsionar.

En El Diario Nacional de Bogotá, fundado por Olaya Herrera, Sonderéguer defendió la reconstrucción de la Gran Colombia, esa alianza entre los pueblos de América del Sur que en la época se conocía como panbolivarismo y recogía el anhelo de Bolívar por crear una federación de países de América (12 de febrero de 1931).

Mundo al Día tituló la entrevista con una frase elogiosa que le dedicó el escritor al diario de Arturo Manrique: "Mundo al Día me ha servido de índice para conocer el movimiento cultural y político de Colombia" (12 de febrero de 1931). El redactor resaltó cómo Sonderéguer se había negado a cambiar de nacionalidad para continuar "su labor en pro de la patria lejana, haciéndola conocer por cuantos medios estuvieron a su alcance y vigilando las noticias que en los diarios se publicaban sobre ella y entrando no pocas veces en polémica cuando así era menester”. Expresó que sentía como obligación trabajar por el progreso de la patria, pero acotó con pesar: "Y yo no he podido cumplir esa obligación". Recalcó también que era necesario rodear al presidente Olaya Herrera, "no crearle obstáculos a su pensamiento de Concentración Nacional”. 
En esta segunda visita a Colombia, Sonderéguer aprovechó para conocer a Cali. El diario Relator destacó las positivas impresiones que tuvo el escritor en esta ciudad donde reiteró sus propuestas de desarrollo, como la colonización de los municipios y la creación de escuelas prácticas de agricultura (27 de febrero de 1931). Por supuesto, aprovechó para hablar de la hacienda pública, de la necesidad de que el liberalismo se actualizara en materia tributaria, de fomentar la agricultura mediante estudios científicos, de la creación de una marina mercante y de una marina de guerra, del fomento de nuevos cultivos y de industrias rurales. Y consideró que uno de los problemas más graves del país era la falta de carreteras y de ferrocarriles, con los que llegaban el progreso y la riqueza. Y esa fue una queja repetida en sus escritos, así como la precariedad del sistema tributario.

En la prensa de la Costa, en sus dos visitas, el escritor villanuevero hizo un llamado a los partidos políticos para trabajar por el bienestar común y zanjar las diferencias por el progreso del país. "La patria está por encima de los partidos", afirmó en El Mercurio de Cartagena retomando la expresión de Benjamín Herrera. Y continuó con esta contundente declaración, más parecida a un programa de gobierno:

Debemos prepararnos para llevar a cabo nuestra segunda guerra de emancipación. Esta será incruenta; pero no ha de ser menos decidida ni menos heroica que la primera. Estoy aludiendo a la emancipación económica [...] Ningún país americano está mejor dotado que el nuestro para esta guerra salvadora. Lo tenemos todo; solo nos falta aprovecharlo [...] Colombia ofrece hoy el espectáculo de un gobierno pobre en un país potencialmente rico. Enriquezcamos al gobierno, sea liberal o sea conservador. Organicemos las finanzas nacionales. Para ello hay que implantar ante todo un sistema impositivo de acuerdo con la capacidad contributiva de la población. He de declarar, aún a riesgo de hacerme impopular, que Colombia es un país sin impuestos. No exagero. Si se comparan las cargas fiscales por habitante de todas las naciones de América, se comprueba que es Colombia donde se paga menos. Esto justifica una reforma. La reforma debe efectuarse con criterio científico, desde luego, y debe abarcar todo el organismo nacional, desde el municipio hasta el Estado. (17 de mayo de 1928)

Fidel Leottau relata que a mediados de marzo de 1931 Pedro Sonderéguer regresó a Buenos Aires a continuar su trabajo de redactor en $\mathrm{La} \mathrm{Na}$ - 
ción. Estando allí, se le notificó su designación como candidato a la Asamblea de Bolívar por el Partido Liberal (Leottau, 2005, p. 218).

\begin{abstract}
Y aunque, según La Nación del 22 de abril de 1931, su elección se consideraba segura, el escritor no parecía dispuesto a ocupar su curul. Se cumplió lo primero: fue elegido; pero no lo segundo, no ocupó su curul. Una nueva noticia de La Nación, aparecida el 19 de julio de 1931, señalaba que Sonderéguer había sido objeto de una despedida por parte de sus compañeros de la sala redacción, ya que se vendría para Colombia a "hacerse cargo de una elevada función pública" [...] En realidad ocuparía dos funciones: la de Jefe de la Comisión Especial de Comercio y la de Tesorero del Partido Liberal [...] Las intenciones de Sonderéguer eran, por supuesto, desarrollar una carrera política en Colombia. Así que el $1^{\circ} \mathrm{de}$ abril de 1932, regresó a Argentina para preparar su viaje definitivo a Colombia. El diario La Nación del 7 de marzo hizo eco de los rumores según los cuales entraría a formar parte del gabinete de Olaya Herrera. (Leottau, 2005, p. 2018)
\end{abstract}

\title{
Agente confidencial del Gobierno colombiano
}

Para entonces, la violencia entre liberales y conservadores y la crisis económica mundial que tuvo su coletazo en Colombia contribuyeron a desgastar el prestigio del presidente Enrique Olaya Herrera, pero un suceso cambió el curso de la historia: la toma de Leticia el 1 de septiembre de 1932, como señala Alberto Donadío en su libro La guerra con el Perú (2002).

Ante la inminencia de la guerra por asuntos limítrofes, Sonderéguer asumió una actitud crítica frente al Gobierno de Lima, como lo señaló en una entrevista a La Nación a su regreso a Buenos Aires donde cuestionó el manejo que le estaba dando al conflicto binacional. Como se verá más adelante, quizá por ello su nombramiento como ministro de Relaciones Exteriores o de Industrias del Gobierno colombiano nunca llegó y el escritor no volvió a Colombia. "Al parecer, esta noticia y algunas diferencias políticas que pusieron en peligro su integridad, obligaron a Sonderéguer a refugiarse definitivamente en la sala de redacción de La Nación, de la cual solo habría de salir cuando fue jubilado" (Leottau, 2005, p. 219).

Una posible pista del giro que tuvieron los acontecimientos puede ser la noticia que registró The New York Times en el sentido de que Sonderéguer habría actuado como agente del Gobierno colombiano en los Esta- 
dos Unidos para buscar respaldo en el conflicto colombo-peruano. En el cable, fechado en Buenos Aires, se lee:

Pedro Sonderéguer, un diputado colombiano que llegó ayer aquí, dijo que Colombia no vacilará en ir a la guerra con Perú si fuera necesario para exigir el respeto por sus derechos en la ciudad de Leticia, ocupada por ciudadanos peruanos el $1^{\circ}$ de septiembre. Leticia y el territorio circundante fueron cedidos a Colombia por el tratado de 1922, y el señor Sonderéguer declaró que para Colombia los tratados limítrofes no eran objeto de revisión, como los tratados comerciales. La junta que se apoderó de Leticia ha pedido al Gobierno de Lima que busque una revisión del tratado y el Gobierno peruano ha indicado a Colombia que quisiera arbitrar la disputa. Mi país — dijo el señor Sonderéguer-, está firmemente determinado a manejar el incidente de Leticia con serenidad, pero también con energía. (The New York Times, 4 de octubre de 1932)

Narra Alberto Donadío que al día siguiente de la invasión a Leticia, el 2 de septiembre, Olaya Herrera "mandó llamar a su despacho, de urgencia, al embajador norteamericano Jefferson Caffery para comunicarle su preocupación por los posibles graves efectos internos e internacionales de la toma de Leticia [... ] Olaya solicitó los buenos oficios del Departamento de Estado. Fue la primera de varias solicitudes en el mismo sentido, que se repitieron tantas veces a partir de ese día, que eventualmente el Departamento de Estado consideró que Colombia pedía a los Estados Unidos que hiciera lo que en realidad correspondía hacer a Colombia" (Donadío, 2002, p. 137). Ello explicaría el papel que desempeñó Sonderéguer, un colombiano conocedor del contexto latinoamericano y cercano a los Estados Unidos, como su admirado Olaya Herrera.

Al año siguiente, el 15 de febrero de 1933, The New York Times sacó una breve noticia titulada "Agent in Argentina resigns" que informa sobre la renuncia de Pedro Sonderéguer como agente confidencial colombiano ("Colombian confidencial agent"), y agrega que este planea regresar a Bogotá el siguiente mes.

Al otro día, El Tiempo de Bogotá publicó un cable de la United Press procedente de Buenos Aires, donde Pedro Sonderéguer "escritor colom- 
biano, exrepresentante a la Cámara de su país [sic] y desde hace años residente en Buenos Aires, declaró hoy a la prensa que el incidente de Tarapacá inicia la guerra entre Colombia y Perú, cuya responsabilidad recae íntegramente sobre este último país. Colombia está plenamente preparada para la guerra; la conquista de Leticia terminará en Iquitos. Colombia defiende en esta guerra el futuro de la paz en América", declaró Sonderéguer a la U.P. (El Tiempo, 16 de febrero de 1933). ${ }^{13}$

Por supuesto, no quedó registro ni ningún allegado supo de la misión secreta de Sonderéguer como agente gubernamental. Lo cierto es que su nombramiento nunca llegó y él no regresó a Bogotá. Este capítulo se cierra con la carta fechada el 15 de septiembre de 1934, que le dirigió Baldomero Sanín Cano a Pedro Sonderéguer donde reproduce el cable que recibió la Legación de Colombia:

\begin{abstract}
Bogotá. 14 de septiembre. 1934. LeColombia. Buenos Aires. Sírvase expresar sinceros agradecimientos al Señor Sondereguer y manifestarle que "visto que la situación que motivó su cargo ha cambiado y partida Defensa Nacional está agotada, cancelócele su nombramiento. Exteriores".
\end{abstract}

El escritor y diplomático le expresa en la misiva su malestar por esta decisión tomada por el Gobierno colombiano, al que Sonderéguer venía sirviendo.

Al revisar la historia del acontecimiento que fue el conflicto fronterizo con el Perú, hallamos un dato significativo para entender la decisión tomada por el Gobierno de Olaya Herrera. Y es que Alfonso López Pumarejo que, como veremos más adelante fue blanco de críticas por parte de Sonderéguer, resultó amigo cercano del nuevo presidente del Perú, el general Óscar Raimundo Benavides, quien reemplazó al asesinado Luis Miguel Sánchez Cerro. Se habían conocido en Londres en sus oficios diplomáticos (Donadío, 2002, p. 255). Incluso López Pumarejo, con el respaldo del pre-

13 Tarapacá, primera población colombiana en la frontera con el Perú, fue declarada objetivo militar por Olaya Herrera para amedrentar al enemigo, ya que allí se asentaron las tropas peruanas después de la toma de Leticia. Pero el combate nunca se dio y los peruanos, alertados por los sobrevuelos de la Fuerza Aérea Colombiana, abandonaron el territorio ocupado (Donadío, 2002, p. 233). 
sidente Olaya Herrera, viajó a Lima para mediar por un arreglo al conflicto en misión no oficial, que por cierto cuestionaron distintos sectores políticos y diarios capitalinos. "Para El Espectador, López incurrió en 'un acto de insurrección personal contra la urbanidad diplomática', pues quien actuaba no era diplomático ni representante de Colombia" (Donadío, 2002, p. 256). Pero las conversaciones tuvieron éxito y en Ginebra se pactó el armisticio el 25 de mayo de 1933.

\section{La muerte y el legado con marca familiar}

Según su biógrafo, Leottau Beleño, no hay evidencias de que Sonderéguer haya regresado a Colombia, pero sí se conservan las innumerables cartas que él y los hijos de sus dos matrimonios le enviaban a la abuela Cayetana Villanueva, que vivía en su pueblo natal (Leottau, 2005, p. 223).

De su primer matrimonio con Blanca Vidal, Pedro Sonderéguer tuvo tres hijos: Conrado, Elsa y Silvia. Y de una segunda unión con Carolina Rodríguez del Pino tuvo dos hijos: César Pedro y Erasmo Pedro. Como se ve, el nombre del escritor marcó y sigue marcando las generaciones. Pedro Conrado Sonderéguer Calveyra (Buenos Aires, 1951), hijo de Conrado, arquitecto, escritor y académico, ha sido el más interesado en rescatar el legado del abuelo. Lo enorgullece saber que se han realizado algunos estudios en el exterior sobre su obra, como el de la estadounidense Kathleen Newman, quien analizó la situación de la mujer en las ciudades latinoamericanas de comienzos del siglo XX basada en sus novelas, publicadas en La Novela Semanal, sección del diario La Nación (Leottau, 2005, p. 232).

María Sonderéguer, que tenía 12 años cuando murió su abuelo, se acuerda de su acento colombiano y de cómo mantenía sus costumbres; le llamaba la atención su gusto por la música popular colombiana, en particular los vallenatos, siendo un intelectual dedicado a sus libros. ${ }^{14}$ Para ella, la obra de su abuelo se podría clasificar en columnas periodísticas sobre la política colombiana y latinoamericana, y sobre temas filosóficos; novelas y libros de filosofía. "Durante los años veinte mi abuelo fue uno de los escrito-

14 Estos comentarios fueron tomados de la entrevista que hizo Julio de La Hoz, antes citada. 
res más prolíficos de La novela semanal, que eran novelas cortas, populares, que se distribuía en los quioscos". Y precisa que en el libro El imperio de los sentimientos (2004), Beatriz Sarlo analiza el fenómeno de producción, distribución y consumo de esas narraciones semanales difundidas en Argentina entre 1917 y 1925 , que le dieron gran popularidad al escritor colombiano. ${ }^{15}$

Sonderéguer murió poco antes de cumplir 80 años, el 8 de octubre de 1964. La Nación lamentó su muerte al tiempo que alabó las virtudes literarias, filosóficas, periodísticas y humanas del escritor colombiano. Igual ocurrió con otros diarios argentinos, como El Mundo, La Razón y La Pren$s a$, que expresaron su consternación por el deceso de Sonderéguer, enterrado en el cementerio de La Recoleta de Buenos Aires.

A su muerte, el diario cartagenero El Universal precisó que el escritor de Villanueva estuvo ausente de su patria por más de medio siglo y solo vino una vez $[s i c]$. "Pudiendo haber sido un lujoso y magnífico representante oficial del país en la patria de Sarmiento, prefirió servirle y darle lustro en el exterior con su obra literaria. En La Nación, tribuna del periodismo "hispanoamericano", Pedro Sonderéguer fue más que un colaborador asiduo, un trabajador al servicio de la cultura, sin renunciar jamás a sus sentimientos patrios, a sus ideales democráticos de genuina estirpe liberal (10 de octubre de 1964).

El diario bogotano El Tiempo registró la noticia veinte días más tarde, el 28 de octubre de 1964, en la sección Cosas del Día. Sobre el pensador y periodista afirmó de manera imprecisa que nació en Cartagena, y que después de vivir años en Argentina regresó al país porque aspiraba a realizar empresas tan arriesgadas como la colonización del Baudó y la construcción de exclusas en el río Cauca por los departamentos de Caldas y Antioquia, con fines hidroeléctricos. Planeó también la construcción de un canal interoceánico para conectar los dos mares y para poblar las ricas poblaciones chocoanas, en lo que pareció emular a su padre, ingeniero civil. Otro de sus ambiciosos proyectos, que promovió después del conflicto con el Perú, fue la colonización de la Hoya Amazónica con la participación

15 Su libro, Cátedra de seducción, fue un best seller en la época, con más de 20000 ejemplares vendidos. 
de Brasil, Ecuador, Perú y Colombia. Suponía la eliminación de barreras aduaneras para estimular la producción agrícola e industrial en el llamado Trapecio (La Nación, 3 de agosto de 1933).

\section{El proyecto colombianista que quedó enterrado}

Pero ningún proyecto obsesionó tanto a Pedro Sonderéguer como convertir al Chocó en potencia nacional. En un artículo publicado en El Tiempo el 26 de diciembre de 1924, se preguntó por qué no se había proyectado un ferrocarril en Quibdó que pusiera a Bogotá en comunicación directa con la Costa Atlántica: "La capital quedaría así unida a los dos océanos, con lo cual ganaría mucho la civilización de la República”. Y termina haciendo un llamado para que el Gobierno se ocupe de la "pintoresca capital chocoana. No es cuerdo dejar al Chocó en el abandono en que se ha tenido hasta ahora $[. .$.$] El porvenir de Chocó es incalculable”.$

Quizá para lograr más rápidamente su propósito acudió a la ficción, género que le había proporcionado miles de lectores en el hemisferio. Así publicó Quibdó, en 1927, que puede leerse como un himno a ese departamento y como una novela de tesis que le pone un escenario paradisiaco y personajes atrayentes a sus ideas sobre la colonización y la inmigración (ojalá europea). Allí ofrece el retrato de una pujante ciudad, habitada principalmente por "blancos", muy diferente de la capital chocoana que hoy conocemos, la más pobre del país y con mayor población de afrocolombianos. Se desconoce cuándo visitó esta región del país, pero tenía información detallada que seguramente le proporcionaban sus fuentes, ${ }^{16} \mathrm{e}$ incluso en su archivo conservaba un mapa hídrico del Chocó fechado en 1928.

Esta novela lo llenaba de orgullo, como se puede inferir por todas las menciones que hizo de ella en distintos momentos de su vida. En El Diario Ilustrado de Santiago de Chile (5 de febrero de 1928) habló así del Chocó:

Hay allí platino, la primera exportación del mundo; oro en cantidades fabulosas, por lo que se le llama "la patria de oro", mezclado con pla-

16 En un artículo del diario Chocó 7 Días (2005), titulado “:Qué sabe usted sobre Pedro Sonderéguer?”, se afirma que esas fuentes fueron los hermanos Jorge y Reinaldo Valencia Lozano, "políticos y periodistas influyentes de la región", según el autor del texto, Édgar Hidalgo T. 
tino se ha descubierto la existencia de radio: caucho, maderas industriales de tintes, plantas medicinales, cacao y muchas otras materias primas. Caudalosos ríos cruzan esta región formando una estructura de comunicaciones de acceso al océano Pacífico. Sirve de capital a esta vasta región, Quibdó, ciudad convertida en la actualidad en una gran factoría con negocios mineros de envergadura, y adonde llegan hombres de todas las regiones del país y del exterior.

Con entusiasmo acumulado, en una entrevista que le hizo Mundo al Día, Sonderéguer pintó la región del Chocó como "una nueva California. Una región de riquezas fabulosas que atrae a hombres de todas las nacionalidades" (12 de febrero de 1931).

Este interés lo llevó a dirigir en 1926 una carta al mandatario del Chocó, Jorge Valencia Lozano, donde le esbozó un proyecto para llevar progreso a la región del Atrato y San Juan. Según sus cálculos, el municipio ${ }^{17}$ podría obtener la concesión dentro de su territorio de unas 20000 ha de baldíos, dividirlas en lotes de 200 ha y distribuirlas entre 100 familias no chocoanas, a las que convocarían por la prensa de grandes ciudades y de La Habana, donde hay muchos españoles. "Para que el Chocó progrese hay que hacer de ella una ciudad populosa”, era su propósito. Lo curioso es que insinuara que fuera poblada por personas "no chocoanas" ( $A B C$, Quibdó, 21 de abril de 1926).

Poco después, en un artículo publicado en El Tiempo, Sonderéguer afirma que Colombia se ha gobernado con torpeza desde que existe, y el principal mal se debe a estar la capital tan lejos de la Costa. Por ello, la mayoría de los lugares costeros están en el abandono. Sugiere nuevamente un plan de acción para el Chocó, retomando las ideas ya expuestas:

Crear en Quibdó una oficina de colonización encargada de medir y dividir las tierras baldías en lotes de doscientas, quinientas y mil hectáreas (no de diez, como disponía el proyecto de un ministro miope, para las selvas orientales). Esa oficina vendería esos lotes a largos plazos a personas que los cultivaran. Podría, además, facilitar semillas e instrumentos de labranza a los cultivadores, que vendrían incluidos en el precio de la tierra. Se me dirá que para realizar ese

17 En realidad, desde 1906 era Intendencia del Chocó, y en 1947 se conformó como departamento. 
plan se necesita dinero y que Colombia no lo tiene. El medio está en la mano: emitir empréstitos y crear impuestos. Colombia es un país sin impuestos y sin deuda (la deuda que tiene es insignificante)... Ofrezco esta brasa para entretenimiento de los señores Nieto Caballero y López Pumarejo y otros economistas colombianos que gusten de jugar con fuego. (EI Tiempo, "Hay que colonizar", 15 de julio de 1926)

El Correo de Colombia, de Medellín (25 de febrero de 1928), recogió la sugerencia de Sonderéguer de que un banco de Medellín fundara una sucursal en Quibdó, para dinamizar los negocios en esta zona del Darién. También creía que, una vez terminada la carretera al Mar, Antioquia podría quedar unida económicamente al Atrato. Finalmente, el periódico manifestó su interés en que se cumplieran los anhelos "del estadista de verdad que es Sonderéguer", y que esas ideas sean sometidas al escrutinio de los financistas de la ciudad.

Valga añadir que después de exponer el plan, siempre aclaraba que para financiarlo el Gobierno debería emitir empréstitos y crear impuestos. Solución repetida una y otra vez como un mantra en sus artículos y entrevistas desde que comenzaron a arreciar sus críticas contra el liberalismo, hacia 1924, porque consideraba que era obligación de ese partido propiciar reformas financieras provechosas para la República.

\section{Liberal a pesar de todo}

El sueño de Sonderéguer con la República Liberal en ascenso — después de cuarenta y cinco años de Hegemonía Conservadora- era que se materializaran audaces programas de desarrollo en Colombia, pero pronto comprendió que no todos los líderes liberales tenían estas miras. Si bien siempre fue un declarado simpatizante del presidente Enrique Olaya Herrera, guardaba sus reservas con Alfonso López Pumarejo, a quien consideraba un propagandista como Joseph Goebbels y calificó su primera presidencia de "palabrera" ( $L a$ Razón, 4 de mayo de 1940). En este artículo del diario bogotano dirigido por Juan Lozano y Lozano, escribió: "Con promesas y disertaciones interminables se apela a los incautos, pero no se ilustra la historia [... ] Suceder a Olaya Herrera fue para el señor López su mayor infortunio. La comparación con el estadista empequeñeció al que solo es un político". 
Prueba este artículo que después de su frustrado cargo en Colombia Sonderéguer no se alejó de la política colombiana y siguió exaltando la memoria de Olaya Herrera, quien falleció en Roma en 1937.

Sus críticas se extendían al partido como tal: "El liberalismo, si en verdad quiere ser un elemento de grandeza para Colombia, debe convertirse en una entidad de espíritu dinámico con un propósito concreto. El liberalismo ha de ser un partido de acción, no de acción revolucionaria, sino de acción civilizadora [... ] Nada más desalentador que ver a algunos liberales (hombres a quienes se supone avanzados) atacar el modernísimo impuesto a la renta con el mismo calor e igual decisión que los más perniciosos políticos conservadores" (El Tiempo, 5 de noviembre de 1924). En plena Hegemonía, azuzaba a su partido para que llegara al Gobierno con "sentido de porvenir". En este mismo artículo, titulado "La misión del liberalismo", agrega: "Hay que trabajar formidablemente en el interior y empinarse para mirar más allá de las fronteras. Colombia, desde el punto de vista internacional, no significa nada. En las conferencias panamericanas — tan ruidosas como inútiles - y en las asambleas de Ginebra, Colombia no representa ni un principio, ni un anhelo, ni una idea. ¿Va comprendiendo el liberalismo cuál es su elevada misión histórica?”, pregunta.

Una y otra vez lanzaba piedras al tejado de su partido:

En el interior, Colombia debería concentrar su esfuerzo a fomentar la inmigración, a construir ferrocarriles y a fundar escuelas. Lo demás vendrá como lógica consecuencia. Inmigrantes, ferrocarriles y escuelas: he ahí un vasto programa de acción y un sólido fundamento de progreso. Mas para realizar ese programa hay que crear rentas públicas, y suprimir ciertos inconvenientes. Si no se acaba con los grandes latifundios, no se puede desarrollar la inmigración. Los inmigrantes no querrán ir a las zonas demasiado apartadas. Mucho bien haría a la Nación si se estableciera un impuesto a la tierra libre de mejoras y se expropiara para subdividirla y venderla a precios razonables [...] Nadie tiene derecho a ser un obstáculo para la prosperidad nacional. ¿Ha pensado la representación parlamentaria del liberalismo en un proyecto de ley sobre inmigración y colonización que consulte los verdaderos intereses del país? ¿Sabe el liberalismo que en el kilómetro 73 del Ferrocarril del Pacífico hay un edificio del Estado que no sirve para nada y que podría ser destinado a hotel de 
inmigrantes? No se han entristecido los patriotas liberales ante la ineptitud del gobierno, que no sabía qué hacer con los doscientos rumanos que llegaron hace algún tiempo a Barranquilla?

Y concluye con tono irónico: "Colombia, que comparte con el Tíbet la triste celebridad de ser gobernada ostensiblemente por el clero, se pasa la vida discutiendo las leyes sobre la prensa, mientras tiene que importar quién prepare las leyes de progreso" (El Tiempo, 5 de noviembre de 1924).

Poco después, el 26 de diciembre de 1924, en el mismo diario bogotano de El Tiempo, arrancó así un artículo titulado "Un ferrocarril indispensable": "He de afirmar una vez más que el deber primordial del Gobierno colombiano es crear rentas, que reemplacen en su oportunidad las cuotas anuales de la indemnización norteamericana [... Como se comprende, solo con dinero podrá el Gobierno trabajar eficazmente en favor de la grandeza patria”.

Y esa grandeza empezaba atravesando el país de "caminos de hierro en todas las direcciones". Su sueño, desde entonces, era "llenar el país de inmigrantes y de líneas férreas". Para él, la inmigración tenía un valor económico y por ello confesó en el artículo que en "momentos de ocio me he entretenido en redactar un plan de estímulo de la inmigración y de la colonización mixta, que a mi juicio daría insuperables resultados”.

Cuando en Colombia apenas se debatían los temas de la inmigración y la colonización, Sonderéguer publicó un artículo titulado "Hay que colonizar” (El Tiempo, 15 de julio de 1926). Allí plantea que uno de los mayores males del país es el regionalismo porque ese apego excesivo a la aldea impide pensar en la nación. Y señala que, a causa de "esa preocupación empequeñecedora y debilitante, no han surgido hombres en Colombia de amplia visión nacional, que estudien el país con criterio de estadistas". Sugiere empezar por el mar y dos de los departamentos que lo bordean: La Guajira y el Chocó.

Allí resulta innegable su visión eurocentrista porque en su proyecto de país civilizado no cabían los negros ni los indios (salvo el futuro presidente, Olaya Herrera, conocido como el "Indio Blanco de Guateque"): 
Entre las zonas que preferentemente deben ocupar la atención de los hombres de gobierno, se hallan el Atrato y la Goajira. Es algo que exaspera pensar que la Goajira, que está a la distancia de un silbido de una frecuentadísima ruta marítima, se encuentre aún poblada de indios semisalvajes. En Bahía Honda se puede crear un puerto admirable y se debe comenzar de inmediato una intensa labor colonizadora. La carretera de Medellín al Golfo de Urabá, proyectada por los antioqueños, puede ser el punto inicial de una vigorosa acción colonizadora en el Atrato. (El Tiempo, 15 de julio de 1926)

Quizá Pedro Sonderéguer siempre supo que la pelea estaba perdida porque Colombia era un país conservador: "A pesar de nuestras continuas veleidades reformistas, los colombianos somos un pueblo de conservadores, esto es, hijo de la falta general de cultura, pues nada es más conservador que la ignorancia", como manifestó en un artículo de El Tiempo (19 de abril de 1923). Allí mencionó que por enfrascarse en los asuntos políticos, los partidos históricos colombianos se habían olvidado de los estudios económicos y de ahí la pobre política financiera.

De esa dimensión económica sí se ocupó Sonderéguer en su rol de periodista con miras a estadista. $Y$ en ese programa de gobierno que dejó disperso en sus textos periodísticos y entrevistas, también incluyó la instrucción pública obligatoria: la apertura de escuelas y universidades para combatir la ignorancia y, por encima de todo, el estudio de la historia patria. Por ello no sorprende que en una nota fechada en 1933, que guardaba en su archivo personal, The New Herald Tribune se refiera a él como "periodista y líder político" y elogie su proyecto sobre la unión de los países con frontera amazónica para fortalecer las relaciones productivas y comerciales con una autopista de 1700 millas a lo largo del río Putumayo. Otro sueño americanista que se quedó atrapado en los mapas y en las cartografías que eran su pasión.

\section{Conclusiones}

Pedro Sonderéguer, considerado por sus compatriotas como crítico, ensayista y sociólogo a la manera del antioqueño Baldomero Sanín Cano, desde el diario La Nación construyó un proyecto americanista inspirado en Ayacucho y en Bolívar, aunque por las vueltas del destino nunca pudo ponerlo a prueba en su patria chica. 
Probablemente la posición americanista de Sonderéguer tuvo su génesis en el diario La Nación, que defendió editorialmente esa bandera, así como el ideal de la patria por encima de los partidos, tan inspirado en Benjamín Herrera como en Bartolomé Mitre. De ese rotativo porteño también heredó el ideario económico, ajeno al intervencionismo estatal — salvo para fomentar la economía - y afecto a los impuestos para garantizar el camino a la prosperidad.

Por ello es paradójico que del escritor que pasó más de cuarenta años de su vida en la redacción de La Nación hasta jubilarse, y publicó en Buenos Aires gran parte de su copiosa obra novelística y filosófica, se conozca tan poco en Colombia como en Argentina. En este último, y otros países del Cono Sur, fue considerado uno de los grandes valores de la intelectualidad hispanoamericana comparable a escritores y políticos colombianos de la talla de Sanín Cano, José Eustasio Rivera, Carlos E. Restrepo y Guillermo Valencia.

Pero seguirán en el misterio las razones por las que no regresó a su país, al que siempre quiso volver para ejercer la política, por lo que renunció a la posibilidad de la ciudadanía argentina que le habría permitido desempeñar cargos públicos en el país de adopción. Se privó así Colombia del aporte de un político humanista que militó en las filas del Partido Liberal.

Quizá su noción del Estado era más avanzada que la de sus copartidarios y sus ideas económicas para transformar el sistema de renta y deuda pública con el fin de encarrillar el país en la vía del progreso asustaron al partido en el poder porque habría perdido popularidad. Ser tan crítico de su partido y de la clase política provinciana le pudo costar su futuro político en el país que había convertido en su laboratorio de observación (tomando prestada la metáfora de Osorio Morales).

A la luz del concepto de biografía intelectual de Dosse (2007), el acontecimiento determinante en la vida de Pedro Sonderéguer como intelectual proyectado a la arena política quedó en la opacidad. Después de establecer posibles conexiones entre su participación activa con el Partido Libe- 
ral, su nombramiento como diputado por el Departamento de Bolívar aun sin presentarse en campaña y, por último, su anunciado cargo en el ministerio de Relaciones Exteriores o en el de Industrias, arriesgamos la hipótesis de que pudieron quedar truncados por varios hechos: las elecciones parlamentarias del 1 de febrero de 1931 (especialmente violentas en los departamentos de Córdoba y Bolívar, donde triunfó ampliamente el liberalismo) y la guerra de Colombia con el Perú donde actuó como agente del Gobierno colombiano en una misión secreta en los Estados Unidos, además de haberse interpuesto en el camino del jefe político del liberalismo, Alfonso López Michelsen. Según su nieto Pedro Conrado también pudo deberse "a la decisión de mi abuela de no acompañarlo, a su frágil inserción en la sociedad colombiana e incluso a no querer arriesgarlo todo (familia, patrimonio, posición, etc. )" ${ }^{18}$

Volver sobre estos hechos tiene sentido en una emergente República Liberal que al romper con cuarenta y cinco años de Hegemonía Conservadora propició el estallido de la violencia política en varias regiones del país. Desde su atalaya del diario La Nación, Pedro Sonderéguer fue testigo de los acontecimientos y quiso tener un mayor protagonismo en esa historia, pero su mismo partido lo excluyó. El acontecimiento se mantiene en este caso como "enigma", pero en una futura pesquisa se podrían seguir otros rastros para establecer una probable causalidad. Por ejemplo, se mirarían esos lugares que fueron escenario de violencia partidista como lugares de la memoria para recontar a manera del "fénix" de Dosse (2013).

También siguiendo a Dosse (2007), a juzgar por el tratamiento que le dio la prensa internacional, nacional y regional (especialmente estas últimas en sus dos visitas a Colombia), fue una figura icónica y respetada por sus múltiples facetas de intelectual, pero al haberse radicado en otro país se convirtió en una especie de intruso en el suyo. Lo castigó ese provincianismo de sus compatriotas que tanto criticó y no pudo servirle a su patria, que fue su mayor deseo.

18 Entrevista realizada en Bogotá el 27 de octubre de 2018. 
Quizá vivir en Argentina tiñó su pensamiento de europeísmo y de ahí sus nociones de progreso ancladas en visiones que hoy veríamos como racistas, pero que estaban normalizadas en el debate público de su época por líderes e intelectuales colombianos de orientación conservadora y liberal, como Laureano Gómez y Luis López de Mesa.

Valga arriesgar que entre las personalidades que mayormente lo inspiraron estuvieron Bartolomé Mitre, quien fundó La Nación cuando dejó la Presidencia, y Enrique Olaya Herrera, quien ocupó el solio presidencial después de haber sido periodista y fundador de diarios. Por algo Sonderéguer dejó en sus archivos unas líneas mecanografiadas, sin fecha, con esta reflexión a manera de epitafio: "No puedo ocultar mi predilección por la prensa ni negarle todo el apoyo de mis facultades. Aspiro a que si mi nombre pasa a la posteridad, quede así grabado: 'Fulano de tal, periodista'. No me preocupa gran cosa que algún erudito agregue: 'Dicen que fue presidente de Colombia'.

Sus aspiraciones fueron altas, pero el país le quedó pequeño. Como mencionó con ironía Alberto Lleras Camargo en esa entrevista que le hizo en 1931, su gran preparación lo imposibilitaba para servirle a Colombia. Por ello, desde la pujante ciudad de Buenos Aires se limitó a observar una patria literalmente chica hasta su muerte.

\section{Referencias}

Barrera, C. (2004). Historia del periodismo universal. Barcelona, España: Ariel.

Diario sobre Diarios. (2010, mayo 20). El periodismo argentino hace 100 años. Recuperado de http://www.diariosobrediarios.com.ar/dsd/ notas/4/303-el-periodismo-argentino-hace-100-anos.php\#.XUGPOlB7mDU

Donadio, A. (2002). La guerra con el Perú. Medellín, Colombia: Hombre Nuevo.

Dosse, F. (2007). El arte de la biografía: entre historia y ficción. Ciudad de México, México: Universidad Iberoamericana. 
Dosse, F. (2013). El acontecimiento histórico entre Esfinge y Fénix. Historia y Grafía, 41, 13-42. Recuperado de http://www.scielo.org.mx/ pdf/hg/n41/n41a2.pdf

Leottau Beleño, F. A. (2005). Villanueva mía, Cartagena de nosotros. Cartagena, Colombia: Guillen Fotolito.

Leottau Beleño, F. A. (2009, junio 7). Pedro Sonderéguer y sus pistas [Entrada blog]. Recuperado de http://blogs.monografias.com/mariagonzalez-rouco/2009/06/07/pedro-sondereguer-y-sus-pistas/

Leottau Beleño, F. A. (2010). Pedro Sonderéguer, el maestro. Magazín del Caribe, 20.

Lleras Camargo, A. (1997). Memorias. Bogotá, Colombia: Banco de la República.

Mayocchi, E. M. (2014, mayo 22). El periodismo argentino hace 100 años. Recuperado en http://www.diariosobrediarios.com.ar/dsd/ notas/4/303-el-periodismo-argentino-hace-100-anos.php

Osorio Morales, J. A. (1964). Volumna Visión de América: “El diario La Nación en la vida argentina”. El Tiempo.

Pons, A. (2010, mayo 31). François Dosse y la biografía intelectual [Entrada de blog]. Recuperado de https://clionauta.wordpress. com/2010/05/31/francois-dosse-y-la-biografia-intelectual/

Sanín Cano, B. (1949). De mi vida y otras vidas. Bogotá, Colombia: ABC.

Sidicaro, R. (1993). La política mirada desde arriba: las ideas del diario La Nación 1909-1989. Buenos Aires, Argentina: Sudamericana.

Sonderéguer, P. (1927). Quibdó. Buenos Aires: Maucci Hermanos. 
Ulanovsky, C. (2011). Historia de los medios de comunicación en Argentina. Paren las rotativas: diarios, revistas y periodistas (1920-1969). Buenos Aires, Argentina: Emecé.

Williams, R. L. (1991). Novela y poder en Colombia 1844-1987. Bogotá, Colombia: Tercer Mundo. 